\title{
ASSESSING PATIENTS’ EXPERIENCE FROM A PRIVATE HEALTHCARE CLINIC BY IMPLEMENTING A SERVQUAL MODEL
}

\author{
Cosmin DOBRIN ${ }^{a^{*}}$, Ruxandra DINULESCU ${ }^{b}$ \\ ${ }^{a, b}$ Bucharest University of Economic Studies, Romania
}

\begin{abstract}
In every healthcare service there is a need to answer patients' feedback and thus, to integrate their visions into quality progress. The purpose of this paper is to create and assess the SERVQUAL scale for analyzing the service quality from a Romanian private healthcare facility. Simultaneously, the study attempts to present the involvement of SERVQUAL in the healthcare services, for measuring service quality. The research included 94 patients, randomly chosen, from a Bucharest private healthcare clinic, during a period of three weeks of collecting data. The results indicated a positive gap for all dimensions, with a slightly decreased value for empathy. After recording the patients' answers, it has been concluded that the level of perception exceeded the expectation's one, therefore the investigated private clinic from Bucharest offers a high satisfaction for patients.
\end{abstract}

KEYWORDS: healthcare services, quality, SERVQUAL

\section{INTRODUCTION}

In present societies, around the world, there is a need to answer patients' needs and requirements by assimilating their visions when considering improving medical services. In Romania, the public and the private healthcare facilities are different in terms of medical services, medical staff's empathy towards the patients, conditions, safety, etc. Therefore, often patients prefer the private medical institutions even if the price per medical service is consistently high.

Even so, both systems (public and private) struggle to offer the patient the best experience, thus their feedback is important for the healthcare managers to see where there are quality gaps that need to be covered. Often, these quality gaps appear when there is a significant difference between expectations regarding the quality of a medical service, and the perceptions of that medical service. As any other customers, patients also come to a specific medical facility having already some expectations about that clinic (for e.g. patients hope to find clean rooms, affordable services, limited waiting time, empathy from the medical staff, etc). Thus, when these expectations are not fulfilled, the patients' satisfaction decreases. In time, these differences (gaps) between patients' expectations and perceptions lead to a negative feedback for the clinic, and a decreasing trust, which in the end, will result in changing the medical service provider. Therefore, the SERVQUAL tool is implemented when analyzing the medical service quality. This instrument is useful for healthcare providers in order to assess the quality dimensions which produce the most significant gap between perceptions and expectations.

\section{LITERATURE REVIEW}

Analyzing service quality has always been a test for every service provider because of the heterogeneous and intangible type of service. Therefore, a tool for measuring service quality, SERVQUAL, was developed by Parasuraman et al. (1985). Basically, the method is used for evaluating the service quality as recognized by the customer.

\footnotetext{
*Corresponding author. E-mail address cosmin.dobrin@man.ase.ro
} 
The service quality is usually developed as the difference between service expectations and actual performance perceptions (Bloemer et al., 1999). Thus, customers assess the quality of a service by making a comparison with the service degree they receive, contrary to the service degree that they would have desired, as well as the service degree they are willing to obtain (Tan \& Pawitra, 2001). However, since expectations generally exceed the actual experience, a limited negative result would represent a good service (Hart, 1996). By developing an empirical test, Parasuraman et al. (1985), created SERVQUAL from a conversion of 10 dimensions, proposed later to 5 dimensions (in 1988) - tangibility, reliability, responsiveness, assurance, and empathy.

Looking at an operational level, the study made on service quality has been influenced by the SERVQUAL method; the tool's base is represented by a so-called gap model. Nowadays, this model is known as an important contribution to the service literature (Parasuraman et al., 1985).

Assessments for the healthcare service having as a base the SERVQUAL tool have been developed in many countries. These researches including the SERVQUAL model contained in- and out-patient services, like interventional procedures and screening. The studies were conducted in countries like: UK (Resnick \& Griffiths, 2011; Youssef et al., 1995; Youssef et al., 1996); Ireland (Koornneef, 2006); Spain (Rincon-Gomez et al., 2011); Portugal (Vinagre \& Neves, 2008); Turkey (Bakar et al., 2008); Egypt (Mostafa, 2005); Iran (Nekoei-Moghadam \& Amiresmaili, 2011); Taiwan (Lin et al., 2009a; Lin et al., 2009b); Korea (Lee \& Yom, 2007); Malaysia (Butt \& De Run, 2010; John et al., 2010); Canada (Tempier et al., 2010); and USA (Anderson, 1995; Anderson \& Zwelling, 1996; Duffy et al., 2001; Reidenbach \& Sandifer-Smallwood, 1990; Strawderman \& Koubek, 2006). Furthermore, the studies concerned different medical services like ophthalmology (Lin et al., 2009b); primary care (Strawderman \& Koubek, 2006); oncology (Anderson \& Zwelling, 1996); and mental health/addiction service (Koornneef, 2006; Resnick \& Griffiths, 2011; Tempier et al., 2010). Moreover, there were also carried studies regarding the attention given by the dentists (John et al., 2010) and nurses (Duffy et al., 2001; Lee \& Yom, 2007).

\subsection{SERVQUAL and GAP Model}

SERVQUAL represents a tool which analysis service quality taking into consideration the Gap model, based on the gap analysis created by Parasuraman et al. (1985). Therefore, in line with this model, there are 5 gaps which serve as the main causes for service quality issues (figure 1).

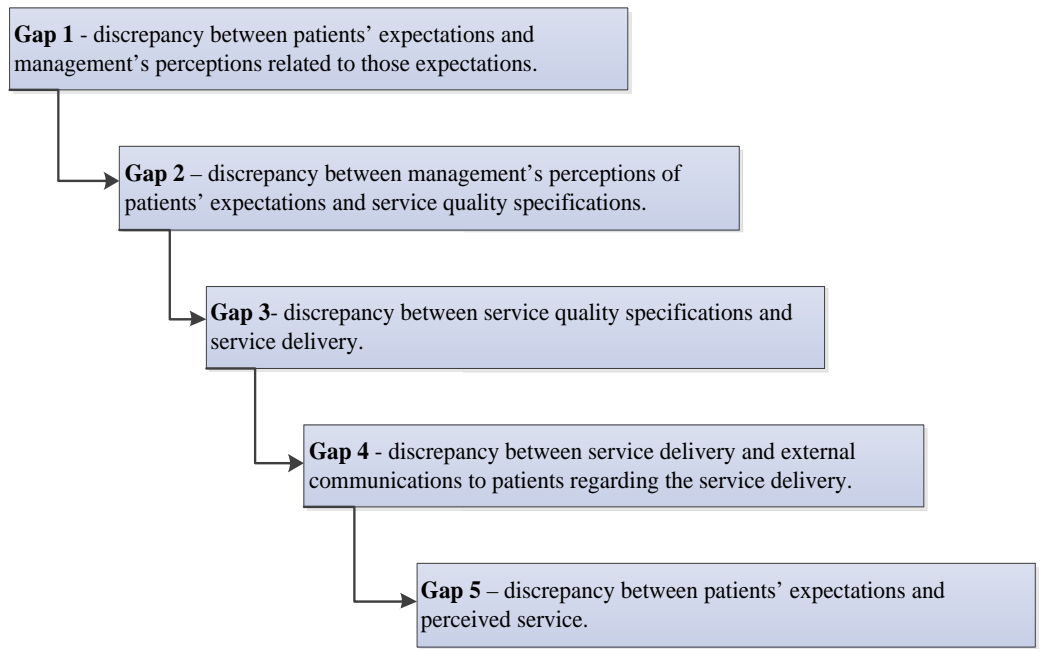

Figure 1. Gap model

Source: Adapted from Zeithaml et al. (1990) 


\section{RESULTS AND DISCUSSIONS}

The demographic profile of the patients illustrated that from the overall 94 patients who visited the private hospital during the current research, the majority of them were females (66\%), $46 \%$ of them were between 36 and 50 years old, and 45\% had master diploma (while 42\% had the bachelor diploma, and 13\% had their high school finished).
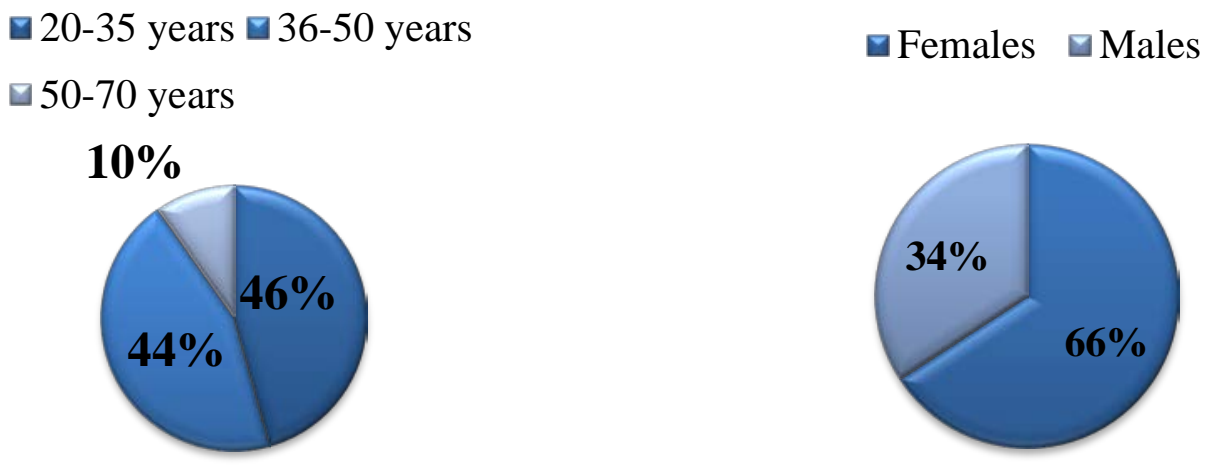

Figure 2. Respondents' age and gender distribution in the SERVQUAL survey Source: The Authors

The proposed survey contained 4 attributes related to tangibility, 5 attributes related to reliability, 4 attributes related to responsiveness, 4 attributes related to assurance and 5 attributes related to empathy:

Table 1. The SERVQUAL questionnaire

\begin{tabular}{|c|c|c|c|c|c|c|c|c|c|c|}
\hline \multicolumn{5}{|c|}{ EXPECTATIONS } & \multirow[t]{2}{*}{ ATTRIBUTES } & \multicolumn{5}{|c|}{ PERCEPTIONS } \\
\hline 1 & 2 & 3 & 4 & 5 & & 1 & 2 & 3 & 4 & 5 \\
\hline \multicolumn{11}{|c|}{ TANGIBILITY } \\
\hline & & & & & Q1. The hospital has modern equipment & & & & & \\
\hline & & & & & Q2. The hospital's physical facilities are visibly appealing & & & & & \\
\hline & & & & & Q3. The hospital's employees have a neat appearance & & & & & \\
\hline & & & & & $\begin{array}{l}\text { Q4. The hospital has visually appealing materials associated with the medical } \\
\text { service (e.g. pamphlets) }\end{array}$ & & & & & \\
\hline \multicolumn{11}{|c|}{ RELIABILITY } \\
\hline & & & & & Q5. When the hospital promises an action by a certain time, it accomplishes it & & & & & \\
\hline & & & & & Q6. When there is an issue, the hospital presents a candid interest in solving it & & & & & \\
\hline & & & & & Q7. The hospital completes the service right the first time & & & & & \\
\hline & & & & & Q8. The hospital implements its services at the promised time & & & & & \\
\hline & & & & & Q9. The hospital insists on having zero errors records & & & & & \\
\hline \multicolumn{11}{|c|}{ RESPONSIVENESS } \\
\hline & & & & & $\begin{array}{l}\text { Q10. The medical staff announces exactly when the medical services will be } \\
\text { achieved }\end{array}$ & & & & & \\
\hline & & & & & Q11. The medical staff offers an accurate service & & & & & \\
\hline & & & & & Q12. The medical staff is always eager to help you & & & & & \\
\hline & & & & & Q13. The medical staff is never too busy to answer to your requests & & & & & \\
\hline \multicolumn{11}{|c|}{ ASSURANCE } \\
\hline & & & & & Q14. The medical staff's behavior inspires confidence in patients & & & & & \\
\hline & & & & & $\begin{array}{l}\text { Q15. You have a feeling of safetiness regarding your transactions with the } \\
\text { hospital }\end{array}$ & & & & & \\
\hline & & & & & Q16. The medical staff is constantly courteous & & & & & \\
\hline & & & & & Q17. The medical staff has the knowledge needed to answer your inquiries & & & & & \\
\hline \multicolumn{11}{|c|}{$\begin{array}{ll}\text { EMPATHY } \\
\end{array}$} \\
\hline & & & & & Q18. The hospital gives you individual attention & & & & & \\
\hline & & & & & Q19. The hospital has a schedule convenient for all its patients & & & & & \\
\hline & & & & & Q20. The hospital has employees who offer you individual attention & & & & & \\
\hline & & & & & Q21. The hospital takes knowledge of your own interests first & & & & & \\
\hline & & & & & Q22. The medical staff understands your exclusive needs & & & & & \\
\hline
\end{tabular}

Source: The Authors 


\subsection{Evaluating the results using the descriptive analysis}

The next step in our research was to compute the Cronbach's alpha coefficients. In order to be considered valid, the coefficients need to have a minimum value of 0.60 , as an indicator of reliability scale (Hair et al., 2009). From table 2 it can be seen that all the attributes' coefficients were higher than 0.70 , except one dimension, "empathy" for expectations, which had an invalid value of 0.46 .

Table 2. SERVQUAL attributes' reliability
\begin{tabular}{|l|c|c|c|}
\hline \multirow{2}{*}{ Dimension } & \multirow{2}{*}{$\begin{array}{c}\text { Number } \\
\text { of } \\
\end{array}$} & $\begin{array}{c}\boldsymbol{\alpha} \text { (reliability } \\
\text { questions }\end{array}$ \\
\cline { 3 - 4 } & 4 & $\mathbf{E}$ & $\mathbf{P}$ \\
\hline Tangibility & 5 & 0.79 & 0.86 \\
\hline Reliability & 4 & 0.82 & 0.92 \\
\hline Responsiveness & 4 & 0.77 & 0.81 \\
\hline Assurance & 5 & 0.46 & 0.85 \\
\hline Empathy & 5 & $\mathbf{0 . 8 9}$ & $\mathbf{0 . 9 7}$ \\
\hline Total & $\mathbf{2 2}$ &
\end{tabular}

The following step was to compute the mean and standard deviation for every variable and dimension, along with the mean gap (defined as the difference between the perception mean and the expectation mean). Depending on the mean's gap result, there might be three situations:

a) If the result is negative $(\mathrm{Pm}-\mathrm{Em}<0)$, it means that the patient is unsatisfied with the medical service;

b) If the result is positive (Pm-Em>0), we assist at a high level of satisfaction from the patient;

c) If the result is equal to $0(\mathrm{Pm}=\mathrm{Em}=0)$, the patient is satisfied with the service (where $\mathrm{Pm}$ represents the perception mean and Em, the expectation mean).

Table 3. Descriptive analysis

\begin{tabular}{|c|c|c|c|c|c|}
\hline \multirow[b]{2}{*}{ Dimension } & \multicolumn{2}{|c|}{ Expectations ( E) } & \multicolumn{2}{|c|}{ Perceptions (P) } & \multirow{2}{*}{$\begin{array}{l}\text { Mean gap result } \\
\text { (P-E) }\end{array}$} \\
\hline & Mean (M) & $\begin{array}{c}\text { Standard } \\
\text { deviation (SD) }\end{array}$ & $\begin{array}{l}\text { Mean } \\
\text { (M) }\end{array}$ & $\begin{array}{c}\text { Standard deviation } \\
\text { (SD) }\end{array}$ & \\
\hline Tangibility & 4.06 & 0.58 & 4.52 & 0.59 & $0.47 *$ \\
\hline Q1 & 4.15 & 0.63 & 4.66 & 0.58 & $0.51 *$ \\
\hline Q2 & 4.00 & 0.81 & 4.44 & 0.77 & $0.44 *$ \\
\hline Q3 & 3.95 & 0.78 & 4.44 & 0.72 & $0.49 *$ \\
\hline Q4 & 4.12 & 0.73 & 4.54 & 0.69 & $0.42 *$ \\
\hline Reliability & 3.86 & 0.74 & 4.33 & 0.76 & $0.48 *$ \\
\hline Q5 & 3.79 & 0.77 & 4.33 & 0.81 & $0.54 *$ \\
\hline Q6 & 3.85 & 0.99 & 4.30 & 0.89 & $0.45^{*}$ \\
\hline Q7 & 3.99 & 0.79 & 4.45 & 0.80 & $0.46 *$ \\
\hline Q8 & 3.89 & 0.85 & 4.29 & 0.91 & $0.40 *$ \\
\hline Q9 & 3.76 & 0.83 & 4.30 & 0.85 & $0.54 *$ \\
\hline Responsiveness & 4.04 & 0.61 & 4.53 & 0.51 & $0.50 *$ \\
\hline Q10 & 3.89 & 0.79 & 4.47 & 0.69 & $0.58 *$ \\
\hline Q11 & 3.95 & 0.88 & 4.55 & 0.72 & $0.60 *$ \\
\hline Q12 & 4.21 & 0.71 & 4.56 & 0.60 & $0.35 *$ \\
\hline Q13 & 4.09 & 0.72 & 4.55 & 0.53 & $0.46^{*}$ \\
\hline Assurance & 4.11 & 0.58 & 4.52 & 0.61 & $0.41 *$ \\
\hline
\end{tabular}




\begin{tabular}{|c|c|c|c|c|c|}
\hline \multirow[b]{2}{*}{ Dimension } & \multicolumn{2}{|c|}{ Expectations ( E) } & \multicolumn{2}{|c|}{ Perceptions (P) } & \multirow{2}{*}{$\begin{array}{l}\text { Mean gap result } \\
\text { (P-E) }\end{array}$} \\
\hline & Mean (M) & $\begin{array}{c}\text { Standard } \\
\text { deviation (SD) }\end{array}$ & $\begin{array}{l}\text { Mean } \\
(\mathrm{M})\end{array}$ & $\begin{array}{c}\text { Standard deviation } \\
\text { (SD) }\end{array}$ & \\
\hline Q14 & 4.06 & 0.75 & 4.48 & 0.64 & $0.42 *$ \\
\hline Q15 & 4.42 & 0.68 & 4.72 & 0.60 & $0.30 *$ \\
\hline Q16 & 3.90 & 0.76 & 4.30 & 0.79 & $0.40 *$ \\
\hline Q17 & 4.05 & 0.71 & 4.56 & 0.73 & $0.51 *$ \\
\hline Empathy & 4.08 & 0.91 & 4.53 & 0.56 & $0.45 *$ \\
\hline Q18 & 3.92 & 0.94 & 4.48 & 0.78 & $0.56 *$ \\
\hline Q19 & 4.10 & 0.78 & 4.80 & 0.57 & $0.70 *$ \\
\hline Q20 & 4.32 & 3.10 & 4.48 & 0.68 & $0.16 *$ \\
\hline Q21 & 4.07 & 0.82 & 4.39 & 0.66 & $0.32 *$ \\
\hline Q22 & 4.00 & 0.88 & 4.52 & 0.72 & $0.52 *$ \\
\hline \multicolumn{2}{|c|}{ Overall satisfaction } & & 4.48 & 0.63 & \\
\hline Note: & ant differen & in response at 19 & & & \\
\hline
\end{tabular}

Source: The Authors

From the above table (table no.3) it can be seen that all the mean gap's results are positive, which indicates that the patients are highly satisfied with all the 22 attributes. However, the only attribute which will need further consideration is Q20, "The hospital has employees who offer you individual attention”, with a result of 0.16 , close to a negative value.

After analyzing the results for each attribute, we can conclude the following:

$\checkmark$ The highest mean for expectations (E) was for the assurance dimension (4.11), which indicates that the patients expect to feel safe around the medical staff, expecting also a degree of courteousity from them, as well as having the needed knowledge to answer their questions;

$\checkmark$ The lowest mean for expectations, respectively, the least expected dimension, is reliability (3.86), meaning that patients do not have great expectations regarding the hospital's interest in their problem, the services completed the right and promised time, or even the zero-errors records. Although this would come as a paradox for the majority of private healthcare facilities (where normally, these would be the most significant attributes taken into consideration), a possible explanation for this result would be the fact that, unfortunately, the Romanian healthcare system has still a lot of gaps that need to be covered, regarding the low quality of the medical service. Therefore, patients start to lower their expectations regarding the medical services, being satisfied only if the medical process (treatments) is correctly administered.

Still, the analyzed private healthcare facility has overcome patients' expectations since the perceptions' results were higher than the expectations' results.

$\checkmark$ The highest positive gap belongs to the item Q19 (The hospital has a schedule convenient for all its patients), meaning that even if sometimes the results are not given at the promised time, at least the hospital adapts its functioning hours according to the patients' needs;

$\checkmark$ On the contrary, the lowest positive gap is still an item from the "empathy" dimension, respectively Q20 (The hospital has employees who offer you individual attention).

\subsection{Evaluating the results using the Relative Importance Index}

The second part of the results came from the analysis of the RII. The relative index analysis was chosen for ranking the criteria taking into consideration their relative importance. The RII was computed both for attributes, as well as for each dimension.

After computing the RII, the attributes and the dimensions were ranked in descendent order.

When analyzing the relative importance score for each attribute, the highest rank was for Q1, followed by Q12 and Q9. This means that it is very important for patients to be treated with modern 
medical equipment, to always have medical staff eager to help them and to go at a clinic where the records present zero errors.

However, the overall RII for the dimensions, presented that reliability has the highest score (0.779), meaning that patients prefer going to a clinic where the services are done right the first time. The results are presented in table 4 and figure 3.

Table 4. RII for each quality attribute

\begin{tabular}{|c|c|c|c|}
\hline Dimension & Attribute & $\begin{array}{c}\text { Relative } \\
\text { importance index } \\
\text { (RII) }\end{array}$ & Rank \\
\hline \multirow[t]{4}{*}{ Tangibility } & Q1 & 0.870 & 1 \\
\hline & Q2 & 0.691 & 13 \\
\hline & Q3 & 0.583 & 19 \\
\hline & Q4 & 0.443 & 22 \\
\hline \multirow[t]{5}{*}{ Reliability } & Q5 & 0.915 & 4 \\
\hline & Q6 & 0.613 & 17 \\
\hline & Q7 & 0.813 & 7 \\
\hline & Q8 & 0.636 & 15 \\
\hline & Q9 & 0.919 & 3 \\
\hline \multirow[t]{4}{*}{ Responsiveness } & Q10 & 0.728 & 12 \\
\hline & Q11 & 0.611 & 18 \\
\hline & Q12 & 0.957 & 2 \\
\hline & Q13 & 0.630 & 16 \\
\hline \multirow[t]{4}{*}{ Assurance } & Q14 & 0.874 & 6 \\
\hline & Q15 & 0.800 & 8 \\
\hline & Q16 & 0.581 & 20 \\
\hline & Q17 & 0.794 & 9 \\
\hline \multirow[t]{5}{*}{ Empathy } & Q18 & 0.774 & 11 \\
\hline & Q19 & 0.647 & 14 \\
\hline & Q20 & 0.562 & 21 \\
\hline & Q21 & 0.904 & 5 \\
\hline & Q22 & 0.781 & 10 \\
\hline
\end{tabular}

Source: The Authors

Figure 3. RII for each quality dimension 


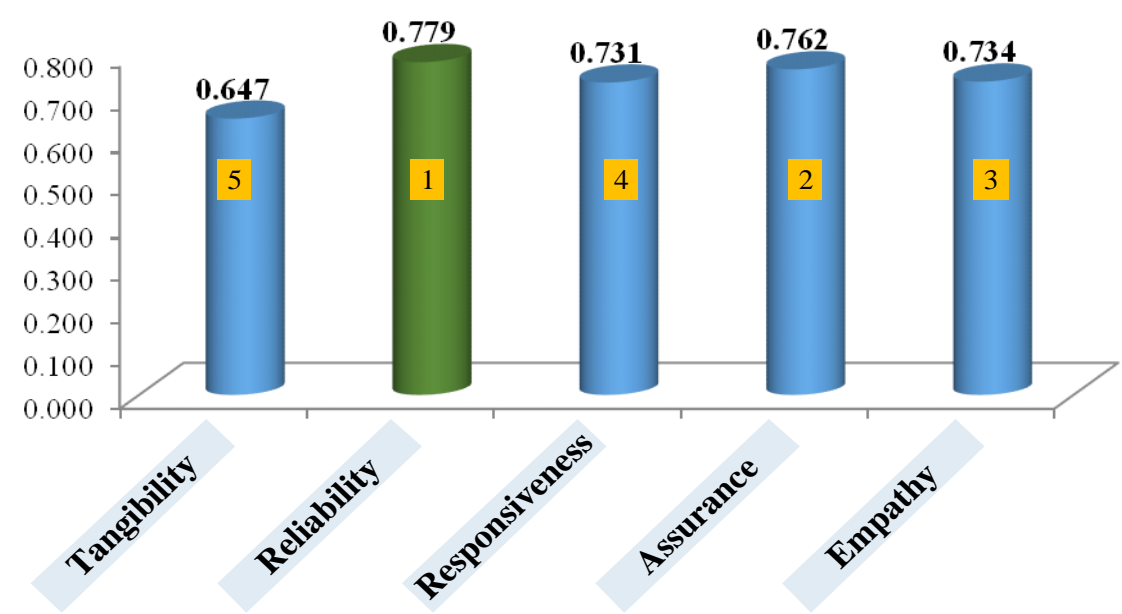

Source: The Authors

\section{CONCLUSIONS AND LIMITATIONS OF THE STUDY}

According to the findings related to the gap analysis the patients perceived medical service quality as satisfying for all the five quality dimensions. Almost all variables (tangibility, reliability, responsiveness, assurance) have demonstrated significant correlation and influence upon patients' satisfaction.

In addition to that, the private hospital should focus on training medical employees to give more attention, even individual attention, to their patients, so that the patients gain a feeling of safety when it comes to the medical service, considering that in comparison with other fields, the healthcare system's customers (the patients) are equally sensitive to tangible and intangible dimensions.

The approach related to analyzing the difference between perceptions and expectations as a SERVQUAL form for computing the gap rate, has proven a utility in determining the levels of medical service quality. The managers can benefit from the information and conclusions gained from the service quality gap and thus to investigate the quality attributes that need a further level of performance.

The current study aimed to present the perceived medical service quality at a private clinic from Bucharest. Considering the satisfaction level of patients, the healthcare managers can determine the present position of their clinic related to whether the clinic meets patients' expectations or not.

As any other study, the current research has some limitations. First of all, the research sample was very limited since the number of investigated patients was pretty low, in comparison with other periods, due to the current worldwide pandemic. In addition to that, safety measures changed drastically since February, when the first case of COVID-19 appeared in Romania.

Second of all, for this kind of questionnaire, the patients are constrained to aggregate their medical quality experiences in a unitary way (for example, the patient is asked to assess the responsiveness and courteousity of medical staff employees, being obliged to choose a single score on the scale, despite the fact that he/she may have had contact with other medical staff who might have had a different behavior or friendliness degree.

\section{ACKNOWLEDGMENT}

"'This study was conducted through the post-doctoral advanced research studies for the academic years 2019-2021, Management field, coordinator The Bucharest University of Economic Studies”. 


\section{REFERENCES}

Anderson, E. A. \& Zwelling, L. A. (1996). Measuring service quality at the University of Texas.

M. D. Anderson Cancer Center. International Journal of Health Care Quality Assurance, 9(7), 9-22.

Bakar, C., Akgun, H. S. \& Al Assaf, A. F. (2008). The role of expectations in patient assessments of hospital care: an example from a university hospital network, Turkey. International Journal of Health Care Quality Assurance, 21(4), 343-355.

Bloemer, J., de Ruyter, K. \& Wetzels, M. (1999). Lining perceived service quality and service loyalty: a multi-dimensional perspective. European Journal of Marketing, 33(11/12), 1082-1106.

Butt, M. M. \& De Run, E. C. (2010). Private healthcare quality: applying a SERVQUAL model. International Journal of Health Care Quality Assurance, 23(7), 658-673.

Duffy, J. A., Duffy, M. \& Kilbourne, W. E. (2001). A comparative study of resident, family, and administrator expectations for service quality in nursing homes. Health Care Management Review, 26(3), 75-85.

Hart, M. C. (1996). Measuring perceptions of quality in NHS clinics using the SERVQUAL methodology. Richargs, B. (Ed.), Healthcare Computing, BJHC, Weybridge

John, J., Yatim, F. M. \& Mani, S. A. (2010). Measuring service quality of public dental health care facilities in Kelantan, Malaysia. Asia-Pacific Journal of Public Health/Asia-Pacific Academic Consortium for Public Health, 23(5), 742-753.

Koornneef, E. (2006). Measuring quality in services for children with an intellectual disability. International Journal of Health Care Quality Assurance, 19(5), 400-408.

Lee, M. A. \& Yom, Y. H. (2007). A comparative study of patients' and nurses' perceptions of the quality of nursing services, satisfaction and intent to revisit the hospital: a questionnaire survey. International Journal of Nursing Studies, 44(4), 545-555.

Lin, D. J., Sheu, I. C., Pai, J. Y., Bair, A., Hung, C.Y., Yeh, Y.H. et al. (2009b). Measuring patient's expectation and the perception of quality in LASIK services. Health and Quality of Life Outcomes, 7(63).

Mostafa, M. M. (2005). An empirical study of patients' expectations and satisfactions in Egyptian hospitals. International Journal of Health Care Quality Assurance, 18(7), 516-532.

Nekoei-Moghadam, M. \& Amiresmaili, M. (2011). Hospital services quality assessment: hospitals of Kerman University of Medical Sciences, as a tangible example of a developing country. International Journal of Health Care Quality Assurance, 24(1), 57-66.

Parasuraman, A., Zeithaml, V. A. \& Berry, L. L. (1985). A conceptual model of service quality and its implications for future research. Journal of Marketing, 4(4), 41-50.

Reidenbach, R. E. \& Sandifer-Smallwood, B. (1990). Exploring perceptions of hospital operations by a modified SERVQUAL approach. Journal of Health Care Marketing, 10(4), 47-55.

Resnick, S. M. \& Griffiths, M. D. (2011). Service quality in alcohol treatment: a research note. International Journal of Health Care Quality Assurance, 24(2), 149-163.

Strawderman, L. \& Koubek, R. (2006). Quality and usability in a student health clinic. International Journal of Health Care Quality Assurance, 19(3), 225-236.

Tan, K. C. \& Pawitra, T. A. (2001). Integrating SERVQUAL and Kano's model into QFD for service excellence development. Managing Service Quality, 11(6), 418-430.

Tempier, R., Hepp, S. L., Duncan, C. R., Rohr, B., Hachey, K. \& Mosier, K. (2010). Patient-centered care in affective, non-affective, and schizoaffective groups: patients' opinions and attitudes. Community Mental Health Journal, 46(5), 452-460.

Vinagre, M. H. \& Neves, J. (2008). The influence of service quality and patients' emotions on satisfaction. International Journal of Health Care Quality Assurance, 21(1), 87-103.

Youssef, F., Nel, D. \& Bovaird, T. (1995). Service quality in NHS hospitals. Journal of Management in Medicine, 9(1), 66-74.

Youssef, F., Nel, D. \& Bovaird, T. (1996). Health care quality in NHS hospitals. International Journal of Health Care Quality Assurance, 9(1), 15-28.

Zeithaml, V., Parasuraman, A. \& Berry, L. (1990). Delivering quality service: Balancing customer perceptions and expectations. New York: The Free Press. 